\title{
Validation of chemical analyses of atmospheric deposition in forested European sites
}

\author{
Rosario MOSELLO*, Monica AMORIELLO ${ }^{1)}$, Tiziana AMORIELLO ${ }^{1)}$, Silvia ARISCI, Andrea CARCANO, \\ Nicholas CLARKE ${ }^{2)}$, John DEROME ${ }^{3)}$, Kirsti DEROME ${ }^{3)}$, Nils KOENIG ${ }^{4}$, Gabriele TARTARI and Erwin ULRICH ${ }^{5)}$ \\ CNR Institute of Ecosystem Study, Largo V. Tonolli 50, 28922 Verbania Pallanza, Italy \\ ${ }^{1)}$ CRA Experimental Institute for Plant Nutrition, Via della Navicella 2/4, 00184 Roma, Italy \\ ${ }^{2)}$ Norwegian Forest Research Institute, Hogskoleveien 12, 1432 Ás, Norway \\ ${ }^{3)}$ Finnish Forest Research Institute, Rovaniemi, P.O. Box 16, 96301 Finland \\ ${ }^{4)}$ Niedersaechsische Forstliche Versuchsanstalt, Graetzelstr. 2, 37079 Goettingen, Germany \\ ${ }^{5)}$ Office National des Forêts, Boulevard de Constance, 77300 Fontainebleau, France \\ *e-mail corresponding author: r.mosello@ise.cnr.it
}

\begin{abstract}
Within the activities of the Integrated Co-operative Programme on Assessment and Monitoring of Air Pollution Effects on Forests (ICP Forests) and of the EU Regulation 2152/2003, a Working Group on Quality Assurance/Quality Control of analyses has been created to assist the participating laboratories in the analysis of atmospheric deposition, soil and soil solution, and leaves/needles. As part of the activity of the $W G$, this study is a statistical analysis in the field of water analysis of chemical concentrations and relationships between ions, and between conductivity and ions for different types of samples (bulk or wet-only samples, throughfall, stemflow) considered in forest studies. About 5000 analyses from seven laboratories were used to establish relationships representative of different European geographic and climatic situations, from northern Finland to southern Italy. Statistically significant differences between the relationships obtained from different types of solutions, interacting with different types of vegetation (throughfall and stemflow samples, broad-leaved trees and conifers) and with varying influence of marine salt were tested. The ultimate aim is to establish general relationships between ions, and between conductivity and ions, with relative confidence limits, which can be used as a comparison with those established in single laboratories. The use of such techniques is strongly encouraged in the ICPF laboratories to validate single chemical analyses, to be performed when it is still possible to replicate the analysis, and as a general overview of the whole set of analyses, to obtain an indication of the laboratory performance on a long-term basis.
\end{abstract}

Key words: atmospheric deposition, ion concentrations, conductivity, data validation

\section{INTRODUCTION}

The Integrated Co-operative Programme on Assessment and Monitoring of Air Pollution Effects on Forests (ICP Forests) and EU Regulation 2152/2003 aim (1) to conduct intensive and continuous monitoring of forest ecosystems in Europe as a means of evaluating the damage caused by atmospheric pollution and other factors influencing forest condition; and (2) to improve the understanding of the causal relationship between changes in forest ecosystems and the factors influencing these changes, with particular focus on atmospheric deposition. In this multi-disciplinary programme, the Expert Panel on Atmospheric Deposition handles all the aspects connected with sampling, analyses, QA/QC, including data validation, and use of the results of atmospheric deposition chemistry. Methods and criteria for harmonised sampling, assessment, monitoring and analysis in the 513 permanent plots located in 31 European countries (de Vries et al. 2003) are formalised in a Manual edited by the ICPF Programme Coordinating Centre in Hamburg (UN-ECE 1998). Despite this basic standardisation of the analytical methods, the comparability of the results of the chemical analyses performed in about eighty laboratories in the different European countries has never been proved. Therefore a Working Group (WG) was created within the Expert Panel on Deposition with the aim to harmonize and improve the QA/QC of chemical analyses of atmospheric deposition (WG on QA/QC). One of the first actions taken by the WG was to update the manual chapter dealing with chemical analyses and QA/QC in laboratories (Lövblad et al. 2004). The new version incorporated the aspects of quality required at all stages of the activity, from the sampling, shipping and treatment of samples to the choice of analytical methods, analyses and validation of results. The adoption of the UNI criteria was strongly recommended and the concept of data validation introduced. Among the different aspects of quality control, special attention was paid to data validation. Three checks of the analytical results are suggested to verify the internal consistency of the data: ion balance, comparison between measured and calculated conductivity, and $\mathrm{Na} / \mathrm{Cl}$ ratio. A fourth check considers the different $\mathrm{N}$ forms, verifying that the sum of 


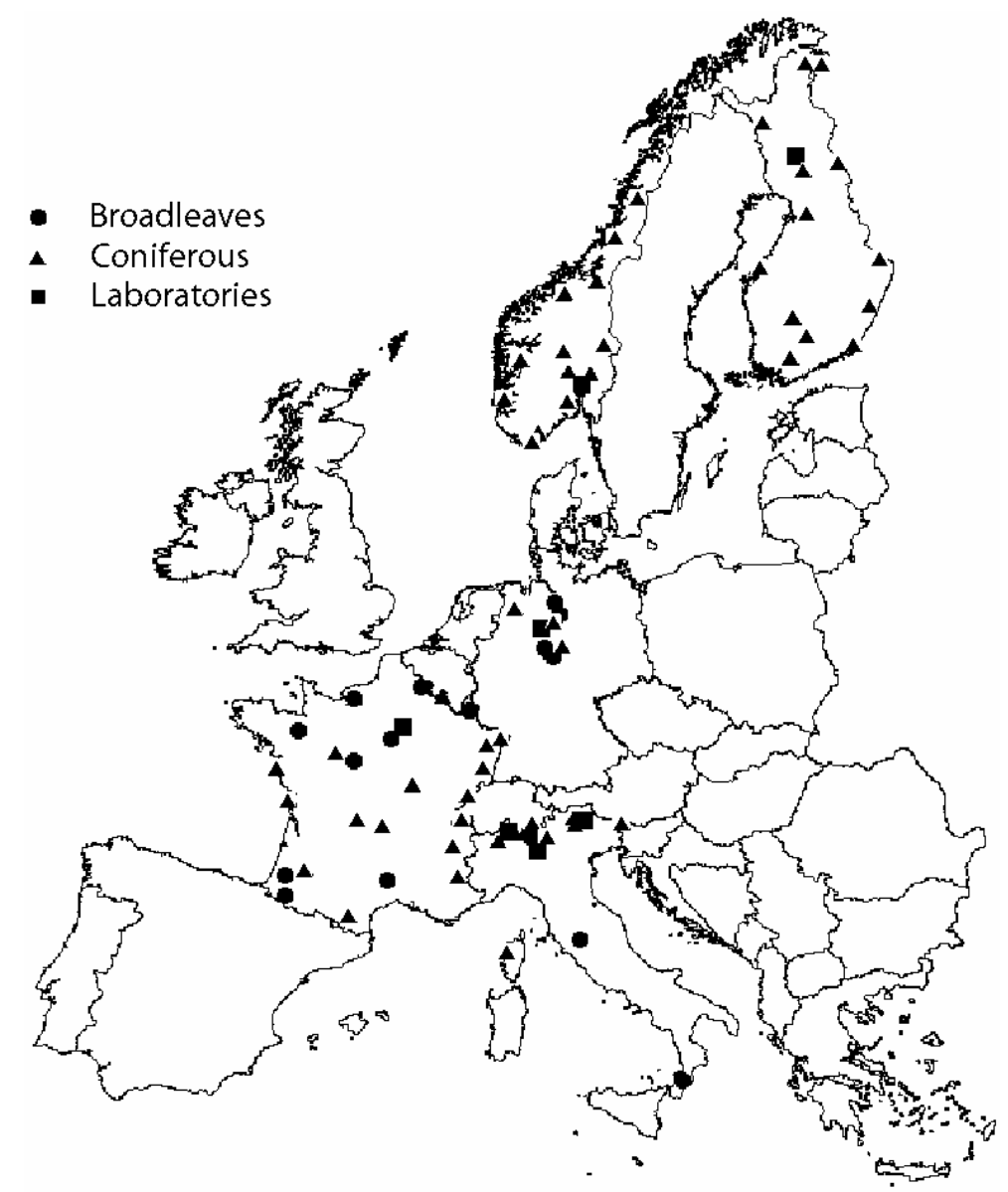

Fig. 1. Location and typology of the forest sampling plots and location of the laboratories involved in the study.

ammonium and nitrate is lower than total nitrogen concentration. The validation of results of water analyses through ion balance and the comparison between measured and calculated conductivity has been proposed and discussed in several handbooks and papers (e.g. A.P.H.A., A.W.W.A., W.E.F. 1998; Rossum 1975; Laxen 1977; Miles \& Yost 1982; Hughens et al. 1994), but most of these were dealing with surface water, open field bulk or wet only deposition (BOF, WET), while a lower number of studies considered the specific problems of throughfall (THR), stemflow (ST) or soil solutions, in which concentrations of organic anions are relatively high. The aspect of the data validation and, more widely, the harmonization of atmospheric deposition measurements are considered in the manuals prepared for the Co-operative Programme for Monitoring and Evaluation of the Long-Range Transmission of Air Pollutants in Europe (EMEP 1996) and the Global Atmosphere Watch of the World Meteorological Organisation (WMO-GAW 2004).

This paper aims to consider the applicability and the limitations of the suggested quality controls (ion balance, comparison between measured and calculated conductivity, and $\mathrm{Na} / \mathrm{Cl}$ ratio) on different types of atmospheric deposition samples collected in the framework of ICP Forests. Five thousand analyses from seven
European laboratories are considered to establish relationships representative of different geographic and climatic situations, from northern Finland to southern Italy. A second aim is to test the use of two new regressions (conductivity vs sum of cations and conductivity vs sum of anions), as tools for the validation of chemical analyses.

\section{METHODS}

Names and acronyms of the laboratories involved in the study are shown in table 1 while figure 1 gives the distribution of the sampling sites considered.

Tab. 1. Laboratories involved in the study.

\begin{tabular}{ll}
\hline IT1 & $\begin{array}{l}\text { Province Environment Protection Agency, Province of } \\
\text { Bolzano, Laives }\end{array}$ \\
IT2 & C.N.R. Institute of Ecosystem Study, Verbania Pallanza \\
IT3 & C.N.R. Water Research Institute, Brugherio \\
FR & SGS Laboratories Wolff-Environment, Evry \\
NO & Norwegian Forest Research Institute, Ås \\
DE & Niedersaechsische Forstliche Versuchsanstalt, Göttingen \\
FI & Finnish Forest Research Institute, Rovaniemi \\
\hline
\end{tabular}

The type of solutions considered (bulk open field, BOF; wet-only, WET; throughfall, THR; stemflow, ST) and the number of samples of each type, related to the 
Tab. 2. Number of samples used for the statistical analysis for each type of solution.

\begin{tabular}{|c|c|c|c|c|c|c|c|c|}
\hline \multirow[b]{2}{*}{ Laboratory } & \multirow[b]{2}{*}{ Bulk open field } & \multirow[b]{2}{*}{ Wet only } & \multicolumn{2}{|c|}{ Throughfall } & \multicolumn{2}{|c|}{ Stemflow } & \multirow{2}{*}{ Marine } & \multirow{2}{*}{ Not marine } \\
\hline & & & Broadleaves & Conifers & Broadleaves & Conifers & & \\
\hline & BOF & WET & THR & THR & ST & ST & & \\
\hline IT1 & 144 & 105 & & 148 & & 42 & 26 & 413 \\
\hline IT2 & 212 & 102 & 217 & 195 & 172 & & 317 & 581 \\
\hline IT3 & 197 & & 61 & 162 & & & 28 & 392 \\
\hline FR & 339 & 228 & 246 & 294 & 118 & 19 & 583 & 661 \\
\hline NO & 326 & & & 327 & & & 239 & 414 \\
\hline DE & 237 & & 248 & 297 & 119 & & 401 & 500 \\
\hline FI & 171 & & & 197 & & & 37 & 331 \\
\hline N. labs & 7 & 3 & 4 & 7 & 3 & 2 & 7 & 7 \\
\hline
\end{tabular}

Tab. 3. Main analytical methods used by the laboratories.

\begin{tabular}{|c|c|c|c|c|c|c|c|c|}
\hline Lab. & $\mathrm{pH}$ & Conductivity & Alkalinity & $\mathrm{NH}_{4}$ & $\mathrm{Ca}, \mathrm{Mg}, \mathrm{Na}, \mathrm{K}$ & $\mathrm{Cl}$ & $\mathrm{NO}_{3}$ & $\mathrm{SO}_{4}$ \\
\hline IT1 & POT GEN & CORR & POT Gran & SPEC Phe & IC & IC & IC & IC \\
\hline IT2 & POT LIS & CORR & POT Gran & SPEC Phe & IC & IC & $\mathrm{IC}$ & $\mathrm{IC}$ \\
\hline IT3 & POT GEN & CORR & POT 2EP & SPEC Phe & $\mathrm{IC}$ & IC & IC & $\mathrm{IC}$ \\
\hline FR & POT GEN & CORR & POT 2EP & IC & IC & IC & IC & $\mathrm{IC}$ \\
\hline NO & POT GEN & $25^{\circ} \mathrm{C}$ & POT 4.5 & CF GD & ICP OES & IC & IC & IC \\
\hline $\mathrm{DE}$ & POT LIS & CORR & POT Gran & CF Phe & ICP OES & $\mathrm{CF} \mathrm{AgCl}$ & $\mathrm{CF} C d$ & ICP OES \\
\hline FI & POT LIS & $25^{\circ} \mathrm{C}$ & POT 2EP & CF GD & IC & $\mathrm{IC}$ & IC & IC \\
\hline \multicolumn{9}{|l|}{ Legend } \\
\hline Acronym & \multicolumn{8}{|c|}{ Method description } \\
\hline POT GEN & \multicolumn{8}{|c|}{$\mathrm{pH}$ - potentiometric with unspecified electrode } \\
\hline POT LIS & \multicolumn{8}{|c|}{$\mathrm{pH}$ - potentiometric with low ionic strength electrode } \\
\hline $25^{\circ} \mathrm{C}$ & \multicolumn{8}{|c|}{ Conductivity - measurement performed at $25^{\circ} \mathrm{C}$} \\
\hline CORR & \multicolumn{8}{|c|}{ Conductivity - measurement performed at different temperature and corrected to $25^{\circ} \mathrm{C}$} \\
\hline POT Gran & \multicolumn{8}{|c|}{ Alkalinity - potentiometric titration with Gran method for extrapolation of the equivalent point } \\
\hline POT 2EP & \multicolumn{8}{|c|}{ Alkalinity - potentiometric titration with two end point extrapolation of the equivalent point } \\
\hline POT 4.5 & \multicolumn{8}{|c|}{ Alkalinity - potentiometric titration with one end point extrapolation of the equivalent point } \\
\hline SPEC Phe & \multicolumn{8}{|c|}{ Ammonium - spectrophotometry indophenol blue method } \\
\hline CF Phe & \multicolumn{8}{|c|}{ Ammonium - continuous flow analysis with indophenol blue method } \\
\hline CF GD & \multicolumn{8}{|c|}{ Ammonium - continuous flow analysis with gas diffusion } \\
\hline IC & \multicolumn{8}{|c|}{ Ion chromatography with chemical or electrochemical eluent suppression } \\
\hline ICP OES & \multicolumn{8}{|c|}{ Inductively coupled plasma optical emission spectrometry } \\
\hline $\mathrm{CF} \mathrm{AgCl}$ & \multicolumn{8}{|c|}{ Chloride - continuous flow analysis with $\mathrm{Ag} / \mathrm{AgCl}$ electrode } \\
\hline CF Cd & \multicolumn{8}{|c|}{ Nitrate - continuous flow analysis with $\mathrm{Cd}$ reduction } \\
\hline
\end{tabular}

laboratories which produced them, are listed in table 2. The results used were validated at national level by the National Focal Centres of ICP Forests and submitted as official results for the years 2002-2003. In addition, for each analysing laboratory, samples were stratified considering the type of solutions, the type of vegetation present in the plot (broadleaves or conifers), and the relative importance of solute of marine origin, assuming a $\mathrm{Cl}^{-}$concentration higher than $50 \mu \mathrm{eq} \mathrm{l}^{-1}$ as a threshold to distinguish between strongly or weakly marine influenced solutions. Table 2 shows that there were great differences in the number of samples for each laboratory and for each type of solution. In particular there were only WET data from 3 labs and ST data from 4. While this unevenness in the stratification of the data does not present problems during the statistical analysis or the construction of the models, the results could be affected by the different weight of each subsample and, especially, by the characteristics and any systematic analytical errors inherent to them.

\subsection{Validation checks and relationships indicated in the ICP Forests manual}

As prescribed by the ICPF manual (Lövblad et al. 2004), each laboratory performs checks of the ionic balance (only BOF and WET) and of the comparison between measured (CM) and calculated (CE) conductivity (on all types of samples), to validate the results. A third check is performed to confirm that the $\mathrm{Na} / \mathrm{Cl}$ ratio is between 0.5 and 1.5 . The instructions contained in the manual are that if the thresholds of these checks are exceeded, the analyses must be repeated; if the result is confirmed and the thresholds are still exceeded, the results must be accepted. In greater detail, the considered relations are: concentration of anions vs concentration of cations ( $\Sigma$ Cat $v s \Sigma$ An) and measured conductivity vs calculated conductivity (CM vs $\mathrm{CE})$, where:

$\Sigma \mathrm{Cat}=\left[\mathrm{Ca}^{++}\right]+\left[\mathrm{Mg}^{++}\right]+\left[\mathrm{Na}^{+}\right]+\left[\mathrm{K}^{+}\right]+\left[\mathrm{NH}_{4}^{+}\right]+\left[\mathrm{H}^{+}\right]$, 
Tab. 4. Concentration units used, factors to transform concentration in $\mu$ eq $1^{-1}$, equivalent conductance at infinite dilution of the single ions.

\begin{tabular}{lccc}
\hline & Unit & Factor to $\mu \mathrm{eq} \mathrm{l}^{-1}$ & $\begin{array}{c}\text { Equivalent conductance at } 25^{\circ} \mathrm{C} \\
\mathrm{kS} \mathrm{cm}^{2} \text { eq }^{-1}\end{array}$ \\
\hline $\mathrm{pH}$ & & $10^{(6-\mathrm{pH})}$ & 0.3500 \\
Ammonium & $\mathrm{mg} \mathrm{N} \mathrm{1}^{-1}$ & 71.39 & 0.0735 \\
Calcium & $\mathrm{mg} \mathrm{l}^{-1}$ & 49.9 & 0.0595 \\
Magnesium & $\mathrm{mg} \mathrm{l}^{-1}$ & 82.24 & 0.0531 \\
Sodium & $\mathrm{mg} \mathrm{l}^{-1}$ & 43.48 & 0.0501 \\
Potassium & $\mathrm{mg} \mathrm{l}^{-1}$ & 25.28 & 0.0735 \\
Alkalinity & $\mathrm{meq} \mathrm{l}^{-1}$ & 1000 & 0.0445 \\
Sulphate & $\mathrm{mg} \mathrm{S} \mathrm{l}^{-1}$ & 62.37 & 0.0800 \\
Nitrate & $\mathrm{mg} \mathrm{N}^{-1}$ & 71.39 & 0.0714 \\
Chloride & $\mathrm{mg} \mathrm{l}^{-1}$ & 28.2 & 0.0764 \\
\hline
\end{tabular}

$$
\Sigma \mathrm{An}=\left[\mathrm{HCO}_{3}^{-}\right]+\left[\mathrm{SO}_{4}^{--}\right]+\left[\mathrm{NO}_{3}^{-}\right]+\left[\mathrm{Cl}^{-}\right]
$$

$$
\mathrm{CE}=\Sigma \lambda_{\mathrm{i}} \mathrm{C}
$$

$\mathrm{i}=\mathrm{H}^{+}, \mathrm{Ca}^{++}, \mathrm{Mg}^{++}, \mathrm{Na}^{+}, \mathrm{K}^{+}, \mathrm{NH}_{4}^{+}, \mathrm{HCO}_{3}^{-}, \mathrm{SO}_{4}^{-}, \mathrm{NO}_{3}^{-}, \mathrm{Cl}^{-}$ $\lambda_{\mathrm{i}}=$ equivalent conductance at infinite dilution of the ion $\mathrm{i}$ (Tab. 4). As the concentrations are expressed in $\mu$ eq $\mathrm{l}^{-1}, \lambda_{\mathrm{i}}$ is given as $\mathrm{kS} \mathrm{cm}^{2} \mathrm{eq}^{-1}$, in order to obtain the conductivity in $\mu \mathrm{S} \mathrm{cm}^{-1}$.

The check of the ion balance is based on the test of electroneutrality of water samples: the total number of negative and positive charges must be equal. The constants required to transform the units used in the ICP Forests Deposition Programme into $\mu \mathrm{eq} 1^{-1}$ are given in table 4 . Using $\Sigma$ Cat and $\Sigma$ An to indicate the concentrations ( $\mu$ eq $\mathrm{l}^{-1}$ ) of cations and anions, respectively, the percentage difference $(\mathrm{PD})$ is:

$$
\mathrm{PD}=100 \times(\Sigma \text { Cat }-\Sigma \text { An }) /(0.5 \times(\Sigma \text { Cat }+\Sigma \text { An })) .
$$

High concentrations of organic matter must be taken into account if present. Organic matter in deposition samples acts as an organic anion, producing a systematic bias in which the concentrations of cations are higher than those of (inorganic) anions. Corrections based on the dissolved organic carbon (DOC) concentration developed e.g. by Oliver et al. (1983) cannot be directly applied to throughfall and stemflow samples, as they were based largely on stream, lake, bog and ground waters, in all of which the DOC is different from that in deposition. Corrections for the presence of dissolved organic matter, specific for each site and each type of sample (bulk deposition, throughfall, etc), can be developed on the basis of the analyses of earlier results.

The percentage difference between measured and calculated conductivity is given by the ratio:

$$
\mathrm{CD}=100 \times(\mathrm{CE}-\mathrm{CM}) / \mathrm{CM} \text {. }
$$

In deposition samples with low ionic strength (below $0.1 \mathrm{meq}^{-1}$ ), the CD value between the measured and calculated conductivity should be no more than $2 \%$ (Miles \& Yost 1982). For an ionic strength higher than $0.1 \mathrm{meq}^{-1}$ and lower than $0.5 \mathrm{meq}^{-1}$ the Davies correction of the activity of each ion can be used, as proposed e.g. by A.P.H.A., A.W.W.A., W.E.F. (1998).
The acceptance threshold values of $\mathrm{PD}$ and $\mathrm{CD}$ adopted by the ICP Forests manual vary with ion concentrations, as expressed in table 5.

Tab. 5. Acceptance threshold values in data validation based on ionic balance and conductivity.

\begin{tabular}{ccc}
\hline Conductivity $\left(25^{\circ} \mathrm{C}\right)$ & $\mathrm{PD}$ & $\mathrm{CD}$ \\
\hline$<10 \mu \mathrm{S} \mathrm{cm}^{-1}$ & $\pm 20 \%$ & $\pm 30 \%$ \\
$<20 \mu \mathrm{S} \mathrm{cm}^{-1}$ & $\pm 20 \%$ & $\pm 20 \%$ \\
$>20 \mu \mathrm{S} \mathrm{cm}^{-1}$ & $\pm 10 \%$ & $\pm 10 \%$ \\
\hline
\end{tabular}

The third relation tested considers the ratio between $\mathrm{Na}^{+}$and $\mathrm{Cl}^{-}$; assuming that most of these ions derive from sea spray, a ratio not far from the marine value (0.86) should be expected (Keene et al. 1986). If other possible sources of these ions are considered, the range of "acceptable" or "not questionable" values is widened from 0.5 to 1.5 (Lövblad et al. 2004).

\subsection{Validation checks and relationships tested in this study}

Before examining the relationships studied using the data from all the laboratories, we should verify by an analysis of the variance that there are no significant differences stratified by type of solutions between the concentrations of anions and cations and between measured and calculated conductivity.

These tests are the premise for a check of the following relationships for the different labs and sample typologies:

1) Sum of cations $\left(\mathrm{H}^{+}\right.$excluded $)$vs $\mathrm{H}^{+}$corrected conductivity ( $\Sigma \mathrm{Cat} v \mathrm{~S} \mathrm{CM}_{\mathrm{H}}^{+}$corr)

2) Sum of anions $v s \mathrm{H}^{+}$corrected conductivity ( $\Sigma \mathrm{An} v s$ $\mathrm{CM}_{\mathrm{H}}^{+}$corr $)$

3) The molar (or equivalent) ratio $\mathrm{Na}^{+} / \mathrm{Cl}^{-}$

$\mathrm{CM}_{\mathrm{H}}{ }^{+}$corr $=\Sigma \lambda_{\mathrm{i}} \mathrm{C}_{\mathrm{i}}$

$\mathrm{i}=\mathrm{Ca}^{++}, \mathrm{Mg}^{++}, \mathrm{Na}^{+}, \mathrm{K}^{+}, \mathrm{NH}_{4}^{+}, \mathrm{HCO}_{3}^{-}, \mathrm{SO}^{--}, \mathrm{NO}_{3}^{-}, \mathrm{Cl}^{-}$

Samples with similar ionic ratios and different ionic concentrations should show a linear correlation between conductivity and the sum of cations and anions. The linearity is valid if the $\mathrm{H}^{+}$concentration is low $(\mathrm{pH}$ higher than 5.0). However, because of the high specific 
Tab. 6. Differences between regressions 1 and 2 tested for the different types of solutions.

\begin{tabular}{ll}
\hline Type of solution & Questions \\
\hline Bulk open field & a) Are there differences among laboratories? \\
Wet only & a) Are there differences among laboratories? \\
Bulk open field+Wet only & a) Are there differences in the regressions between the two types of solutions? \\
& b) Are there differences between marine/non-marine samples? \\
Throughfall & a) Are there differences among laboratories? \\
& b) Are there differences between solutions from broadleaf/conifer plots? \\
& a) Are there differences among laboratories? \\
btemflow & b) Are there differences between solutions from broadleaf/conifer plots? \\
& c) Are there differences between marine/non-marine samples? \\
Throughfall+Stemflow & b) Are there differences between solutions from broadleaf/conifer plots? \\
& c) Are there differences between marine/non-marine samples?
\end{tabular}

electric conductance of $\mathrm{H}^{+}\left(0.350 \mathrm{kS} \mathrm{cm}^{2} \mathrm{eq}^{-1}\right.$ at $25^{\circ} \mathrm{C}$, table 4), compared to that of the other ions (range 0.044 - $0.080 \mathrm{kS} \mathrm{cm} \mathrm{eq}^{-1}$ ), small variations in $\mathrm{H}^{+}$ concentrations produce relatively strong variations in conductivity. In these cases, a conductivity value corrected for the contribution of hydrogen ion can be used:

$$
\mathrm{CM}_{\mathrm{H}}{ }_{\text {correct }}=\mathrm{CM}-\lambda \mathrm{H}^{+} \times\left[\mathrm{H}^{+}\right]=\mathrm{CM}-0.35 \times 10^{-\mathrm{pH}}
$$

where the conductivities are expressed as $\mu \mathrm{S} \mathrm{cm}^{-1}$ at 25 ${ }^{\circ} \mathrm{C},\left[\mathrm{H}^{+}\right]$as $\mu$ eq $\mathrm{l}^{-1}$.

As the relation between ion concentrations and conductivity is a chemical-physical law, it might be expected that no differences exist between the CM vs $\Sigma$ Cat or CM vs $\Sigma$ An regressions in different types of aqueous solutions (BOF, WET, THR, ST, stream and lake water, etc.). On the other hand, as the equivalent conductance of the ions is slightly different, the chemical composition, considered as ratio between ions, might influence the values of the regression. Furthermore, deposition samples are far from being perfect solutions, as in most cases they contain organic substances, suspended particulate matter, etc. These compounds may vary markedly with the type of vegetation and the remoteness of the area. A further factor of confusion in checking for general regressions between conductivity and ions is the presence of random or systematic errors affecting chemical analyses. As the aim of the paper is to provide general regressions between conductivity and cation or anion concentrations, with an indication of the associated errors, before pooling the data we conducted a statistical analysis to test for systematic differences due to (1) systematic errors in laboratories, (2) type of vegetation in the plot and (3) influence of marine salt, which may produce major changes in the ion ratios. The rationale for the checks is given in table 6 .

\subsection{Statistical treatment of the data}

The analysis of covariance (ANCOVA) is the statistical method used to test differences among laboratories, between types of samples, between solutions from broadleaf/conifer plots and between "marine" and "non-marine" solutions. This analysis represents an integration of the analysis of variance and the regression analysis and is appropriate when there are both quantitative and qualitative (grouping) factors. The basic advantage of this analysis is a reduction in the bias caused by the differences existing between groups before experimental treatments are administered. The ANCOVA model treats both between-group and regression variance as systematic components. The statistical model is:

$$
\mathrm{y}_{\mathrm{ij}}=\beta_{0}+\tau_{\mathrm{i}}+\beta_{1} \times\left(\mathrm{x}_{\mathrm{ij}}-\mathrm{x}_{\mathrm{i}}\right)+\varepsilon_{\mathrm{ij}}
$$

where:

$\mathrm{y}_{\mathrm{ij}}=$ dependent variable score of $\mathrm{j}^{\text {th }}$ unit (cation or anion) in $i^{\text {th }}$ treatment;

$\beta_{0}=$ population mean (of dependent variable) common to all observations;

$\tau_{\mathrm{i}}=$ effect of treatment, which assumes a different role:

- laboratory i (a constant associated with all units in laboratory i);

- type i of solutions: BOF, WET, BOF+ WET, THR, $\mathrm{ST}, \mathrm{THR}+\mathrm{ST}$;

- solutions from broadleaf/conifer plots;

- "marine" and "non marine" solutions.

$\beta_{1}=$ linear regression coefficient of $\mathrm{y}$ on $\mathrm{x}$;

$\mathrm{x}_{\mathrm{i}}=$ mean of all units on covariate conductivity;

$\mathrm{x}_{\mathrm{ij}}=$ covariate score for $\mathrm{j}^{\text {th }}$ unit in $\mathrm{i}^{\text {th }}$ laboratory;

$\varepsilon_{i j}=$ error component associated with $j^{\text {th }}$ unit in $i^{\text {th }}$ treatment.

Simple linear regressions are used to build a statistical model to predict cation $\left(\mathrm{H}^{+}\right.$excluded) or anion concentrations beginning from the values of conductivity $\left(\mathrm{H}^{+}\right.$corrected). The statistical model is equal to the previous term $\tau_{\mathrm{i}}$ without treatment. Both ANCOVA and regression analysis are analyzed through the general linear models (GLM) procedure. This procedure uses the method of least squares to fit the general linear model and handles models relating one or several continuous dependent variables to one or several independent variables. The independent variables may be either classification variables, which divide the observation into discrete groups, or continuous variables. For the ratio $\mathrm{Na} / \mathrm{Cl}$, an ANOVA was 
Tab. 7. Percent of validated data based on ion balance and conductivity tests (see Tab. 4) and mean conductivity and ion concentrations of the pooled analyses from the 7 laboratories. PD and CD are calculated on the mean values. Units: conductivity $\mu \mathrm{S} \mathrm{cm}^{-1}$ at $25^{\circ} \mathrm{C}$; ion concentrations $\mu$ eq $1^{-1}$.

\begin{tabular}{cccccccccc}
\hline $\begin{array}{c}\text { Type of } \\
\text { solution }\end{array}$ & $\begin{array}{c}\text { Number of } \\
\text { samples }\end{array}$ & $\Sigma$ An & $\Sigma$ Cat & $\begin{array}{c}\text { ion balance } \\
\text { \% valid }\end{array}$ & PD & CM & CE & $\begin{array}{c}\text { CM vs CE } \\
\text { \% valid }\end{array}$ & $\begin{array}{c}\text { CD } \\
\text { BOF }\end{array}$ \\
\hline WET & 435 & 122 & 130 & 74 & 6.3 & 19.3 & 18.6 & 91 \\
THR & 2392 & 236 & 277 & 34 & 16.0 & 36.8 & 34.6 & 80 & -3.7 \\
ST & 428 & 394 & 467 & 32 & 17.0 & 60.5 & 55.7 & 69 \\
\hline
\end{tabular}
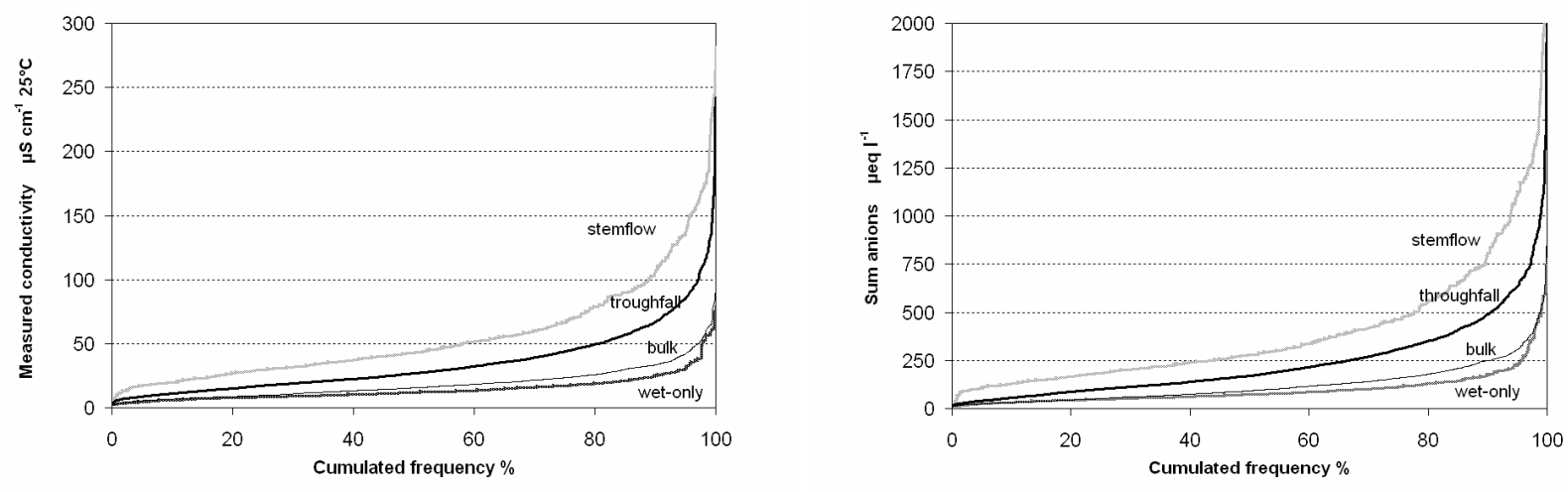

Fig. 2. Cumulative frequency curves of measured conductivity and sum of anions for different types of atmospheric deposition.

performed on the different types of samples, the different characteristics of the vegetation (broadleaves, conifers), and the contribution of marine spray in the ion composition of deposition.

\section{RESULTS AND DISCUSSION}

\subsection{Relationships tested in each laboratory}

The checks of the ion balance and the comparison between measured and calculated conductivity, already performed by each laboratory, were re-evaluated following the criteria of table 5; the results are presented in table 7 . The same table shows the mean values of the sum of anions, cations, measured and calculated conductivity; more detailed information on the data distribution is provided in figure 2 , which shows the cumulative frequency curves of the sum of the cations and the conductivities for the four different types of solution. It emerges clearly from the figure that the chemical characteristics of WET and BOF samples are very similar, while THR and ST solutions show markedly higher ion concentrations.

The ion balance test shows the best results for WET, followed by BOF samples; in contrast, the percentage of acceptable results is very low in the case of THR and ST, because of the high incidence of organic anions. This is in agreement with the mean concentrations of cations and anions, with percent differences which are markedly higher for THR and ST (16 - 17\%) than for WET, BOF (5.0 - 6.3\%). This was largely expected and is in agreement with the manual, which gives this test as indicative only in the case of WET and BOF solutions.
The conductivity test is also reliable for THR and ST solutions, even if some systematic errors are probably present in the evaluation of the calculated conductivity, corrected for ionic strength, as this is regularly lower than the measured values. Table 7 also give the values of conductivity corrected for the $\mathrm{H}^{+}$contribution; these are only slightly lower than the full values, as the $\mathrm{pH}$ of the solutions in most cases is higher than 5.5, indicating low $\mathrm{H}^{+}$concentrations.

\subsection{Relationships tested in this study: regressions between conductivity and ions}

Before testing the relationships between conductivity and ions, we applied a simple analysis of variance to check for statistical differences among anions and cations in the various laboratories (Tab. 8). There is no evidence of differences for the wet only type of solution, whereas there is appreciable evidence for bulk solution and strong evidence for throughfall and stemflow solutions.

Tab. 8. Significance of analysis of variance ( $p$-value) on test " $\Sigma$ Cat vs $\Sigma \mathrm{An} "$ and "Measured Conductivity vs Calculated Conductivity".

\begin{tabular}{cccc}
\hline Type of solution & Number of labs & $\Sigma$ Cat $v s \Sigma$ An & CM vs CE \\
\hline BOF & 7 & 0.023 & 0.116 \\
WET & 3 & 0.501 & 0.551 \\
THR & 7 & 0.001 & 0.005 \\
ST & 3 & 0.001 & 0.079 \\
\hline
\end{tabular}


Tab. 9. Regression equations, coefficients of determination and $95 \%$ confidence limits for cations and anions for each type of solution. Units: cation, anion concentrations $\mu$ eq $1^{-1}$, Conductivity $\mu \mathrm{S} \mathrm{cm}^{-1}$ at $25^{\circ} \mathrm{C}$.

\begin{tabular}{|c|c|c|c|}
\hline Type of solution & Model & $\mathrm{R}^{2}$ & Confidence Limits \\
\hline BOF & $\Sigma \mathrm{Cat}_{\mathrm{H}}^{+}$excluded $=-7.87+7.99 \times \mathrm{CM}_{\mathrm{H}}^{+}$corr & 0.97 & \pm 39 \\
\hline WET & $\Sigma \mathrm{Cat}_{\mathrm{H}}^{+}$excluded $=-19.47+8.79 \times \mathrm{CM}_{\mathrm{H}}^{+}$corr & 0.97 & \pm 29 \\
\hline $\mathrm{BOF}+\mathrm{WET}$ & $\Sigma \mathrm{Cat}_{\mathrm{H}}^{+}$excluded $=-8.86+8.08 \times \mathrm{CM}_{\mathrm{H}}^{+}$corr & 0.97 & \pm 38 \\
\hline THR & $\Sigma \mathrm{Cat}_{\mathrm{H}}^{+}$excluded $=-2.13+7.97 \times \mathrm{CM}_{\mathrm{H}}^{+}$corr & 0.97 & \pm 74 \\
\hline ST & $\Sigma \mathrm{Cat}_{\mathrm{H}}^{+}$excluded $=-10.33+8.00 \times \mathrm{CM}_{\mathrm{H}}^{+}$corr & 0.99 & \pm 71 \\
\hline $\mathrm{THR}+\mathrm{ST}$ & $\Sigma \mathrm{Cat}_{\mathrm{H}}^{+}$excluded $=-2.70+7.96 \times \mathrm{CM}_{\mathrm{H}}^{+}$corr & 0.98 & \pm 74 \\
\hline $\mathrm{BOF}$ & $\Sigma \mathrm{An}=-1.63+7.64 \times \mathrm{CM}_{\mathrm{H}}^{+}$corr & 0.97 & \pm 34 \\
\hline WET & $\Sigma \mathrm{An}=-10.33+8.55 \times \mathrm{CM}_{\mathrm{H}}{ }_{\text {corr }}$ & 0.98 & \pm 28 \\
\hline $\mathrm{BOF}+\mathrm{WET}$ & $\Sigma \mathrm{An}=-2.82+7.75 \times \mathrm{CM}_{\mathrm{H}}^{+}$corr & 0.97 & \pm 33 \\
\hline THR & $\Sigma \mathrm{An}=-15.80+7.41 \times \mathrm{CM}_{\mathrm{H}}^{+}$corr & 0.98 & \pm 65 \\
\hline ST & $\Sigma \mathrm{An}=-38.09+7.68 \times \mathrm{CM}_{\mathrm{H}}^{+}$corr & 0.98 & \pm 99 \\
\hline $\mathrm{THR}+\mathrm{ST}$ & $\Sigma \mathrm{An}=-18.96+7.47 \times \mathrm{CM}_{\mathrm{H}}^{+}$corr & 0.98 & \pm 72 \\
\hline
\end{tabular}

The same analysis is used to verify whether statistical differences occur between measured conductivity and calculated conductivity for different types of solution (Tab. 8). Statistically significant differences are detected only for throughfall solution ( $p$-values $=0.005)$. These results are entirely in agreement with the observations in the previous section relating to the checks performed in individual laboratories (Tab. 7).

The analysis of covariance, where treatment is equal to laboratory, indicates a strong statistical significance for all groups. On the other hand, the average response differs significantly from group to group. This is an indication of systematic errors in the measurements performed in the laboratories. However, as the variability percentage of the adopted model explained by "laboratory" treatment is very small (the range varies from $0.008 \%$ to $1 \%$ ), no large error can derive from ignoring this factor. We will not therefore take the "laboratory" factor into account in the following elaborations, considering the data as deriving from a single sample.

In the same way, the analysis of covariance, applied to the "marine/non-marine" solution treatment, shows that there is no evidence of difference between "marine" and "non-marine" solutions for cations in the BOF + WET and ST solutions, or for anions in the THR, ST and THR + ST solutions; on the other hand, there are differences for anions in the BOF + WET solutions $(p$ value $=0.001)$ and for cations in the THR and THR + ST solution ( $p$-value $=0.003$ and 0.009 , respectively). However, also in this case the differences are quite small, accounting for a total of $0.05 \%$ of the total variance attributable to the model. Therefore, these differences too were treated as negligible.

According to the analysis of covariance for treatment equal to vegetation, there is no evidence of any difference between broadleaf/conifer plots for anions $(p$-value $=0.19)$ in the THR and THR + ST solutions, or for cations in the THR + ST solutions. In the other cases, cations in THR solution and anions and cations in ST solution, these differences are statistically significant ( $p$-value $=0.008$ and 0.001 , respectively) but once again negligible, as this factor has an impact of $0.3 \%$ at the most on the variance explained by the model under consideration.

After establishing that the above factors had an impact of at most $1 \%$ on the total variance of the model, we calculated the regressions, distinguishing only between the different types of solution (Tab. 9). All the models are highly significant $\left(\mathrm{R}^{2}=0.97\right.$ or $0.98, p$-value $=0.0001)$. The CLs are relatively small for BOF and WET samples (ranges 29 - $39 \mu \mathrm{eq}^{-1}$ for cations, and 28 - $34 \mu$ eq $1^{-1}$ for anions), larger for THR and ST samples (71- $74 \mu \mathrm{eq} \mathrm{l}^{-1}$ for cations, 65 - $99 \mu \mathrm{eq} \mathrm{l}^{-1}$ for anions). Examples of these relationships are shown in figure 3 .

The CL of THR and ST are larger than those of BOF and WET, probably because of the higher presence of organic compounds, which on the one hand represent a cause of variability and on the other may influence the correctness of the analyses of some of the inorganic constituents, e.g. alkalinity. The different number of laboratories contributing to the data of WET vs THR samples (3vs 7, Tab. 2) may explain the narrower CL of the regressions for the former type of solution; this hypothesis does not seem to work in the case of THR vs ST samples, where CL for ST solutions (3 labs) are about the same or even higher than CL for THR solutions (7 labs, tables 9 and 2).

The regressions obtained can be used in the following way to test the consistency of experimental values of CM and the sum of anions or cations: enter the $\mathrm{CM}$ values and get the predicted $\Sigma$ Cat or $\Sigma$ An value. The experimental value of $\Sigma C$ at or $\Sigma A n$, to be accepted, should be included in the range "predicted value \pm the CL intervals".

\subsection{Relationship tested in this study: $\mathrm{Na} / \mathrm{Cl}$ ratio}

Sodium and chloride in atmospheric deposition may be influenced by the relative importance of different inputs: natural marine (sea spray) and continental (wind borne mineral dust) sources, anthropogenic emissions, leaching of leaves or vegetation (Cornu et al. 1998; Stallard \& Edmond 1981). A common assumption is 

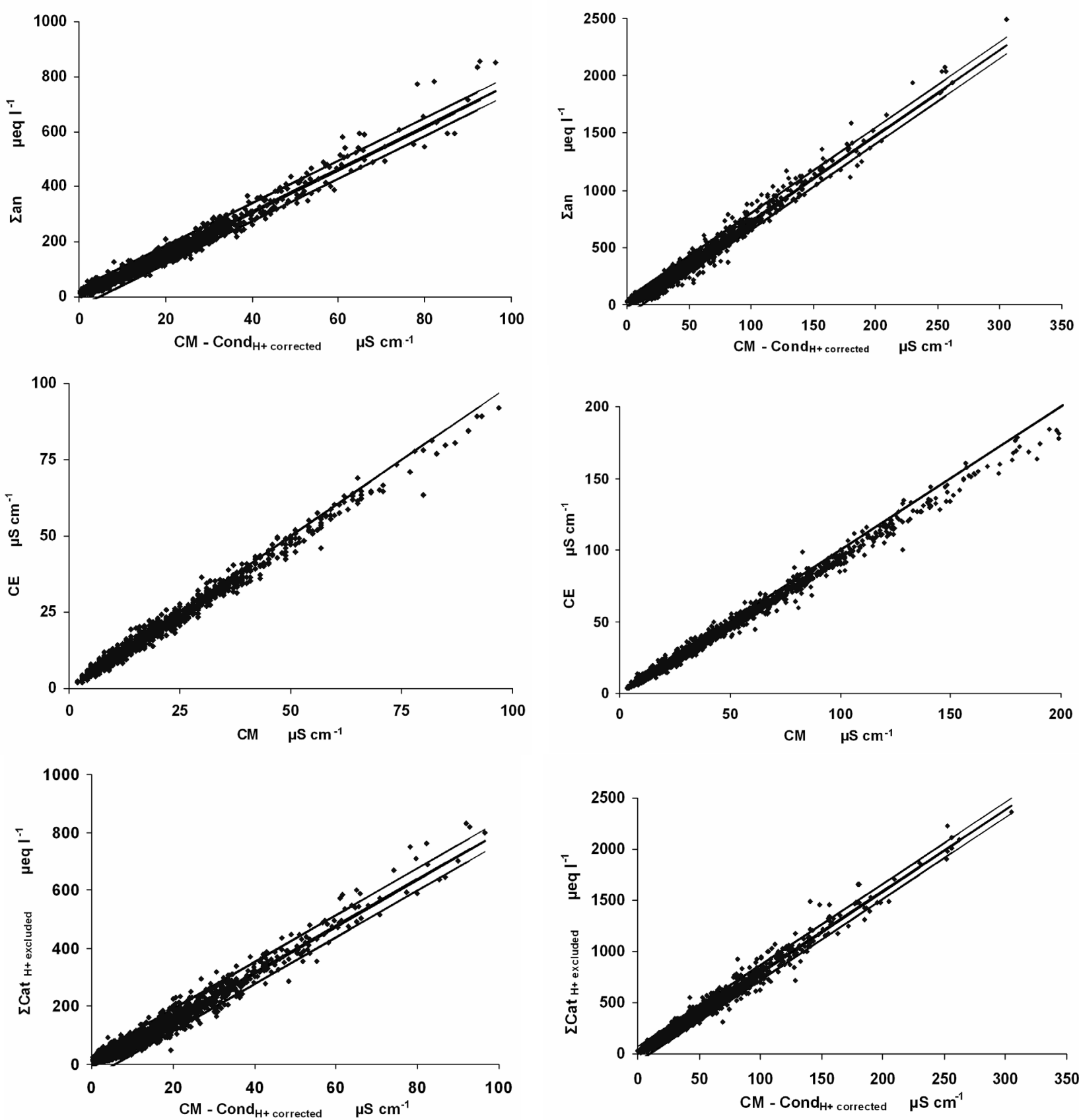

Fig. 3. Relationships between sum of anions and conductivity $\left(\mathrm{H}^{+}\right.$corrected $)$, measured and calculated conductivity, compared with the 1:1 line; relationships between conductivity $\left(\mathrm{H}^{+}\right.$corrected $)$and sum of cations $\left(\mathrm{H}^{+}\right.$excluded $)$compared with regression lines and $95 \% \mathrm{CL}$, for bulk+wet deposition (left) and throughfall+stemflow (right).

that most of the chloride is from sea-spray, and that the contribution of marine ions in atmospheric deposition is in the same ratio as in sea water; these assumptions lead to a "sea-salt correction" being used to eliminate this source of variability. The molar or equivalent ratio $\mathrm{Na} / \mathrm{Cl}$ in sea water is 0.86 (Broecker 1974), so this value is often used as a reference in analyzing results. If we take other possible sources into account, the acceptance range of the $\mathrm{Na} / \mathrm{Cl}$ ratio must be widened from 0.5 to
1.5 for the measurement to be considered reliable. This range, adopted in the ICP Forests data validation, was tested using the available pool of data. As a preliminary step, an ANOVA was performed to test for significant differences among laboratories, for marine and nonmarine solutions (threshold $\mathrm{Cl}$ concentration higher or lower than $50 \mu \mathrm{eq} \mathrm{l}^{-1}$ ), and for the "vegetation" treatment (broadleaves or conifers). Results showed that at least one of the labs displayed systematic differences 
Tab. 10. Mean values of the $\mathrm{Na} / \mathrm{Cl}$ ratios in the different labs and $95 \% \mathrm{CL}$ for each type of solution, stratified between marine and non-marine $\left(\mathrm{Cl}^{-}\right.$threshold $\left.50 \mu \mathrm{eq}{ }^{-1}\right)$.

\begin{tabular}{|c|c|c|c|c|c|c|c|c|}
\hline Type of solution & & $\mathrm{DE}$ & FR & FI & IT2 & IT3 & $\mathrm{NO}$ & Total \\
\hline \multirow[t]{3}{*}{$\mathrm{BOF}$} & M & $0.99 \pm 0.06$ & $0.84 \pm 0.03$ & - & $0.92 \pm 0.08$ & - & $0.96 \pm 0.07$ & $0.91 \pm 0.04$ \\
\hline & NM & $1.20 \pm 0.03$ & $0.84 \pm 0.03$ & $1.28 \pm 0.07$ & $1.13 \pm 0.05$ & $1.15 \pm 0.09$ & $1.21 \pm 0.04$ & $1.13 \pm 0.02$ \\
\hline & Total & $1.15 \pm 0.05$ & $0.84 \pm 0.10-$ & $1.28 \pm 0.07$ & $1.07 \pm 0.10$ & $1.15 \pm 0.10$ & $1.15 \pm 0.04$ & $1.08 \pm 0.02$ \\
\hline \multirow[t]{3}{*}{ WET } & M & - & $0.87 \pm 0.05$ & - & $0.94 \pm 0.43$ & - & - & $0.89 \pm 0.15$ \\
\hline & NM & - & $0.91 \pm 0.02$ & - & $1.39 \pm 0.18$ & - & - & $1.06 \pm 0.06$ \\
\hline & Total & - & $0.90 \pm 0.21$ & - & $1.32 \pm 0.10$ & - & - & $1.03 \pm 0.06$ \\
\hline \multirow[t]{3}{*}{ BOF+ WET } & M & - & $0.85 \pm 0.03$ & - & $0.92 \pm 0.13$ & - & - & $0.91 \pm 0.04$ \\
\hline & NM & - & $0.88 \pm 0.02$ & - & $1.23 \pm 0.07$ & - & - & $1.12 \pm 0.02$ \\
\hline & Total & - & $0.87 \pm 0.10$ & - & $1.15 \pm 0.10$ & - & - & $1.07 \pm 0.02$ \\
\hline \multirow[t]{3}{*}{ THR } & M & $0.85 \pm 0.02$ & $0.78 \pm 0.02$ & $0.65 \pm 0.19$ & $0.89 \pm 0.16$ & $*$ & $0.95 \pm 0.05$ & $0.84 \pm 0.03$ \\
\hline & NM & $1.04 \pm 0.02$ & $0.74 \pm 0.02$ & $1.16 \pm 0.08$ & $1.20 \pm 0.09$ & $0.84 \pm 0.06$ & $1.12 \pm 0.05$ & $1.03 \pm 0.03$ \\
\hline & Total & $0.95 \pm 0.12$ & $0.77 \pm 0.12$ & $1.08 \pm 0.13$ & $1.12 \pm 0.12$ & $0.81 \pm 0.13$ & $1.04 \pm 0.05$ & $0.95 \pm 0.02$ \\
\hline \multirow[t]{3}{*}{ ST } & M & $0.78 \pm 0.07$ & $0.86 \pm 0.05$ & - & $0.93 \pm 0.06$ & - & - & $0.87 \pm 0.04$ \\
\hline & NM & $1.02 \pm 0.08$ & $0.94 \pm 0.07$ & - & $1.39 \pm 0.11$ & - & - & $1.09 \pm 0.05$ \\
\hline & Total & $0.88 \pm 0.13$ & $0.89 \pm 0.13$ & - & $1.03 \pm 0.05$ & - & - & $0.94 \pm 0.03$ \\
\hline \multirow[t]{3}{*}{$\mathrm{THR}+\mathrm{ST}$} & M & $0.84 \pm 0.02$ & $0.78 \pm 0.02$ & & $0.91 \pm 0.09$ & - & - & $0.84 \pm 0.03$ \\
\hline & NM & $1.04 \pm 0.02$ & $0.74 \pm 0.02$ & - & $1.22 \pm 0.08$ & - & - & $1.03 \pm 0.02$ \\
\hline & Total & $0.94 \pm 0.11$ & $0.79 \pm 0.11$ & - & $1.10 \pm 0.11$ & - & - & $0.95 \pm 0.02$ \\
\hline
\end{tabular}

compared with the whole group of labs; this lab was not considered in the following elaboration. The ANOVA on the remaining pool of data showed a significant variance $(p$-value $=0.0001)$ and a fraction of explained compared with the total variance between 4 and $13 \%$ for the "laboratory" factor and between 1 and $9 \%$ for the "marine" or "non-marine" factor; on the other hand, the ANOVA did not find significant differences between THR and ST solutions for the "vegetation" treatment. Finally the mean $\mathrm{Na} / \mathrm{Cl}$ ratio and the $95 \% \mathrm{CL}$ was calculated for all types of solutions (BOF, WET, THR, ST), stratifying on the $\mathrm{Cl}^{-}$concentrations (marine, nonmarine and total), both for the whole group and for the single labs (Tab. 10). If we look at the overall ratios, the values for BOF and WET are higher than those for THR and ST. A comparison of the two types of precipitation, stratified on $\mathrm{Cl}^{-}$concentration, shows that the ratio is lower for marine samples $(0.84-0.91)$, than for nonmarine samples $(1.03$ - 1.09). In conclusion, the results from a set of samples of atmospheric deposition of highly heterogeneous environmental origin suggest that a $\mathrm{Na} / \mathrm{Cl}$ ratio outside the range from 0.5 to 1.5 is highly improbable.

\section{CONCLUSIONS}

This study confirmed that the chemical and chemical-physical laws which determine the relationships between anions, cations and measured conductivity offer a unique possibility to test the internal consistency of the analyses of major inorganic compounds in atmospheric deposition. As for the ion balance, some care is needed in the case of solutions with high concentrations of organic substances (THR and ST), where an excess of cations $v s$ inorganic anions is systematic.
As part of the internal quality control of chemical analyses by the laboratories participating in the ICPF monitoring, the ion balance and conductivity tests are indicated as valuable for checking the analyses, and threshold values are given. The elaboration performed in this paper confirmed the validity of the ion balance tests, restricted to BOF and WET solutions, while in the case of THR and ST the presence of organic anions determines concentrations of cations systematically higher than those of inorganic anions. The comparison between measured and calculated conductivity proved to be less restrictive than the ion balance for BOF and WET; furthermore it also proved to be valid for THR and ST, because of the negligible contribution of organic matter to conductivity. A further criterion suggested by the ICPF manual is to check the $\mathrm{Na} / \mathrm{Cl}$ ratio, which should not be too far from the marine ratio (0.86), with a tolerance range between 0.5 and 1.5 . The analyses performed in the seven labs confirmed a mean $\mathrm{Na} / \mathrm{Cl}$ ratio of between 0.94 and 1.08 ; if the $95 \%$ limits of the CL are taken into account, the range increases to $0.9-1.1$.

Using the same chemical-physical criteria, this study tested two more regressions, between measured conductivity (corrected for the $\mathrm{H}^{+}$contribution) and (a) the sum of the cations, $\mathrm{H}^{+}$excluded, and (b) the sum of the anions. The absence of statistical differences between the data produced by the different labs made it possible to pool them, stratified according to types of solutions, and to obtain general relationships. The resulting regressions and the relative CLs may be used as a comparison for testing the agreement between conductivity and sum of cations (or anions) in a single analysis. To this end, the predicted $\Sigma$ Cat or $\Sigma$ An of the analysis under consideration can be derived from the $\mathrm{CM}$ value using the general regression; the measured value of $\Sigma$ Cat or $\Sigma$ An, to be acceptable, should fall in 
the range "predicted value \pm the CL intervals". A further use of the proposed general regressions is a comparison with similar regressions performed on sets of data obtained in other laboratories.

In conclusion, the topics considered in the paper largely confirm that it is possible and helpful to use the chemical-physical properties of dilute solutions in testing the internal consistency of chemical analyses. These tests, easily performed with a simple electronic spreadsheet, should be a routine phase of the analysis, aimed at data validation. The tests must be performed soon after the end of the analyses, so that if some of the tests fail, the analyses can be repeated; if the anomalous results are confirmed, they should be accepted. A further advantage of these checks is the identification of writing errors, whose contribution to the general reliability of a database is not negligible.

\section{ACKNOWLEDGMENTS}

The authors acknowledge the financial contributions of the European Commission and national agencies. Italian data were produced in the framework of the Italian National Programme for Forest Ecosystem Monitoring (CONECOFOR), co-ordinated by Corpo Forestale dello Stato and co-funded by the European Commission (under EC Regulation no. 2152/2003 Forest Focus). We acknowledge Dr Raffaella Balestrini (CNR Water Research Institute, Brugherio, Italy) and Danilo Tait (APPA Bolzano, Italy) for information and details on the analytical methods. Suggestions and criticisms by Dr Peter Waldner (WSL, Bismendorf, Switzerland) improved the manuscript.

\section{REFERENCES}

A.P.H.A, AWWA \& WEF. 1998. Standard methods for the examination of water and wastewater. $20^{\text {th }}$ ed. American Public Health Association, Washington.

Broecker, W.S. 1974. Chemical Oceanography. Harcourt Brace Jovanovich, Inc., New York.

Received: July 2005

Accepted: September 2005
Cornu, S., J.P. Ambrose, Y. Lucas \& T. Desjardins. 1998. Origin and behaviour of dissolved chlorine and sodium in Brazilian rainforest. Wat. Res., 32: 1151-1161.

De Vries, W., G.J. Reinds, M. Posch, M.J. Sanz, G.H.M. Krause, V. Calatayud, J.P. Renaud, J.L. Dupouey, H. Sterba, E.M. Vel, M. Dobbertin, P. Gundersen, J.C.H. Voogd. 2003. Intensive monitoring of forest ecosystems in Europe. Technical Report 2003. EC, UN-ECE. Brussels, Geneva: $161 \mathrm{pp}$.

EMEP 1996. Manual for sampling and chemical analysis. Kjeller, Norwegian Institute for Air Research (EMEP/ CCC-Report 1/95) (Newest revision in 2001).

Keene, W.C., A.A. P. Pszenny, J.N. Galloway \& M.E. Hawley. 1986. Sea-salt correction and interpretation of constituent ratios in marine precipitation. J. Geophys. Res., 91: 6647-6658.

Hughes, S.G., E.L. Taylor, P.D. Wenzell, R.F. Mccurdy \& R.K. Boss. 1994. Models for conductance measurements in quality assurance of water analysis. Analytical Chemistry, 66 (6): 830-835.

Laxen, D.P.H. 1977. A specific conductance method for quality control in water analysis. Wat. Res., 11: 91-94.

Lövblad, G., R. Mosello, J. Derome, E. Ulrich, K. Derome, N. Clarke, N. Koenig, G.P.J. Draajers. 2004. Sampling and analysis of deposition. Part VI. In: UN-ECE. 1998. Manual on methods and criteria for harmonised sampling, assessment, monitoring and analysis of the effects of air pollution on forests. Hamburg.

Miles, L.J. \& K.J. Yost. 1982. Quality analysis of USGS precipitation chemistry data for New York. Atmosph. Env., 16: 2889-2898.

Oliver, B.G., E.M. Thurman, \& R.L. Malcom. 1983. The contribution of humic substances to the acidity of colored natural waters. Geochim. Cosmochim. Acta, 47: 20312035.

Rossum, J.R., 1975. Checking the accuracy of water analyses through the use of conductivity. Journal American Water Works Association, 67: 204-205.

Stallard, R.F. \& J.M. Edmond. 1981. Geochemistry of the Amazon 1. Precipitation chemistry and the marine contribution to the dissolved load at the time of peak discharge. J. Geoph. Res., 86: 9844-9858.

UN-ECE. 1998. Manual on methods and criteria for harmonised sampling, assessment, monitoring and analysis of the effects of air pollution on forests. Hamburg.

WMO GAW 2004. Manual for the GAW precipitation chemistry programme. Guidelines, data quality objectives and standard operating procedures. WMO TD No. 1251. 